\title{
Online Learning Community and its Application in the Occupational Training of College Teachers
}

\author{
Xiu Guo Huang \\ School of Interpretation \& Translation, Shandong University at Weihai. Weihai, Shandong Province, PRC,264209 \\ Email:xiuguohuang@126.com
}

\begin{abstract}
Object: The analysis of established online learning community, and its structural elements and creation strategies can shed light on the effect of the application of online learning community in the occupational training of college teachers. Methods: detailed analysis of the existing successful online Teacher learning communities like the Wired for Learning and the online learning community established by Beijing Normal University. Conclusion: Traditional learning community took place in a specific physical environment, whose members and resources are limited by the physical environment. Online learning community can help solve many of the existing problems in traditiona training and opened new possibilities for occupational training
\end{abstract}

\section{Introduction}

At present wireless network technology has covered our whole country, and mobile intelligent terminal has been widely used and popularized. This tremendous change has exerted its influence on every facets of our life. Considering the rapid development of information technology and the reform in every respects of our society that it has brought about, we realized that the traditional occupational training for college teachers was destined to be changed. And the internet innovation has already had a profound influence on the traditional way of learning and the training mode.

The online teacher learning community assisted by the network technology enabled teachers to circumvent the limitation and restriction of time and space that dominated the traditional learning environment. In the online teacher learning community, the teachers were offered more chances of participation and resource sharing. They can also have more accesses to interaction in various forms and at different time. The construction of online teacher learning community contributed to the depth and breadth of the study and research in the information era. Through the network environment, online teacher learning community is bound to play a great role in promoting the development of teachers' professional development.

\section{Literature Review}

The "community" of the online learning community was originally a sociological term, which referred to a kind of organic collective existence and the integration of the people inside it. Later it was introduced to the field of education and therefore the concept of "learning community" emerged. Now, the paradigm of teacher's professional development has changed from passive training into active learning, whose 
core include the "teacher's knowledge of teaching, the cognitive process of teachers, teachers' acquisition of knowledge, and how to understand and apply knowledge to the classroom situation"[1]. Avalos pointed out that the cooperative learning community of teachers was to assist and stimulate teachers' acquisition of knowledge and became an important intermediary of teachers learning. Learning community refers to a community composed of learners and learning helpers. The members in learning community frequently communicate and exchange information between them, share all sorts of study resource, and fulfill some learning tasks. Thus the mutual influence and interpersonal connection among its members are formed and can contribute to the development of teachers' profession [2]. As to what kind of situation is most appropriate for teachers to update knowledge, increase knowledge and put into class practice, "community" has become an ideal place for teachers' learning and the mainstream discourse in teachers' occupational training. The goal of learning community is through the growth of collective knowledge; an increase in the individual knowledge can be achieved.

Dewey in his work Democracy and Education first introduced the term "community" into the field of education, whose goal is through exemplary demonstration and mutual encouragement, to create a mutual learning atmosphere for learners. In this way it can improve the learners' enthusiasm for study. Bruner in its research also pointed out in the process of learning the importance of the creation of a "community". The concept of "learning community" reflected the belief that "education is a way of life", whose purpose is to break the fixed boundaries of education, realize the lifelong development of the individual. After Giovanni studied different types of schools, he believed that schools should be reformed into community. Through a commitment to community, concept, intention, values, feelings and beliefs in Community, a link among members can be established, which emphasizes the formation and identification of the common identity of learners.

The concept of "community" stressed that through participation, cooperation and dependence on each other, support and negotiations throughout these processes, gradually a common goal, memory, communication ability, toolkit, and specification can be established. Ultimately, the identity characterized by community membership was consolidated"[3]. For members of a specific learning community, the mutual communication, sharing of learning experience and learning materials, with the other members of the community can positively influence each other and make each learner get the support and nurture. At present, the concept of "learning community" has taken root in education and teaching situation, the related research and practice of "learning community" has become a kind of "international movement".

\section{Analysis and Evaluation of Online Learning Community in Occupational Training of College Teachers}

The analysis of established online learning community, and its structural elements and creation strategies can shed light on the effect of the application of online learning community. At present the most successful of online learning community of this type include the Lab.net that aimed to help middle school teachers' career development, and Wired for Learning, a collaborative Learning community built by IBM to help students and teachers to form a meaningful connection in the process of communication and through collaborative tools to help teachers improve teaching. Besides inside China, the influential and successful example is the virtual learning community, an intelligent network teaching support platform, 
built by the Capital Normal University, to provide the support for the sharing of learning resources, offer a variety of teaching and learning tools, and ease the burden of teachers to conduct online classes and students' cognitive load. Their improvement in teaching efficiency and quality has been proved in the empirical research.

Traditional learning community took place in a physical environment, whose members and resources are limited by the physical environment. While the online learning community is formed in the digital and virtual space, members and the resources enjoyed great flexibility. Online learning community realized the sharing of resource in the true sense and changed their way of learning and collaboration, which really enhanced the learning effect of the members of the community. The development of information technology makes it possible for the wide employment of E-learning and M-learning. Now we are moving toward U-learning, where learning can happen in any forms and at any time. These new learning concepts broke the pattern of traditional learning and made learning merge naturally into our lives. This new type of learning, a truly personalized learning, was no longer restricted by time and place. Learning resources don't just refer to traditional learning materials, such as books, notes, but all the the bits of information on the Internet, such as text, audio, video, images, and so on.

The online learning community can play a major role in the college teachers' career development. The main advantage of online learning community derives from the support of information technology that specially focused on the activity of community members, resource sharing, technology tools and relations between them. This can definitely promote the technical level of teachers' professional development. Online learning community can also strengthen the collaboration of the teachers. It is highly flexible in time and space and is suitable for the synchronous learning, asynchronous learning and group learning activities. In addition, the online learning community will help to optimize the spread of practical knowledge and thus improve teachers' occupation development. Aided by the tools, the resources and activities on the community platform, tacit knowledge can be innovated and practical knowledge can be transmitted outward. The collective sharing and internal absorption of useful information can be achieved.

The online learning community made it possible to solve many of the existing problems in the teachers' occupational development. First, in traditional teaching occupational training, in most cases, the learners are isolated from each other and therefore limited to one's own development. There are certain interactive learning activities among each other but the number is small and the effect is quite limited. Online learning community is able to strengthen mutual cooperation. Based on the digital technology, it is highly flexible in time and space and is suitable for the synchronous learning, asynchronous learning and group learning activities. Through mutual cooperation, the common professional development can be achieved. Second, the current knowledge sharing is still in a state of disorder and cannot realize effective sharing with others. For example, by cloud technology, computer can meet the demand of large data and information processing, where "the cloud" resource is accessible anywhere any time. But it is still necessary, through the appropriate construction of facilities, to separate the function of the resource from its entity, and to realize the integration and flexible configuration of resources. Only through this can the advantage of the congregation, sharing and update of resources be achieved [4]. Through the integration of the resources on the internet community platform, we can best share and absorb the collective resources.

According to Gattiker et al. (2000) research, 
online learning community should possess a few essential elements, which include a social network based on personal relations, a simple and open communication channel inside the community that is accessible to all interested groups, private meetings and mutual understanding, dialogue, feedback, a common experience and a common history. We can analyze these elements in a detailed way. The primal factor in the online learning community is the community members that are the various participants of an online learning community, such as various kinds of ordinary members and team leaders. As for the occupational training of college English teachers, any online learning community of this kind must have enough interested members. Secondly, the online learning community should also be equipped with the appropriate technical tools, such as those that are used to support a variety of community learning activities such as efficient search engines, management tools, communication tools, collaboration tools, and the like. Besides, the online learning community also should have a central subject. This is initiated by the community organizer or by some members of the community and it should be of mutual interest, it is the focus of the target community activities. In the case of college English teachers occupational development, the topics would better include but not limited to the following topics like big classroom teaching, lesson preparation, choice of teaching resources, the academic development and so on. The online learning community should possess enough resources, various resources like multimedia and interactive digital resources, and also human resources in a broader sense. For example, the online learning community for college English teachers, there should be a balance of the number of inexperienced young teachers and experienced teachers to achieve the desirable effect. In a word, online learning community is a condensed experience of all the community members, which can turn a traditional "resource distribution center" into an "interactive platform" in a true sense.

\section{Findings and Suggestions}

After the analysis and evaluation, we can say that in the construction of online learning community, special attention must be paid to the following factors.

4.1 A clear and precise definition of the theme of the online learning community.

The theme must be pertinent to the promotion of the teachers' professional development, resources improvement and the teaching of a particular major. It also should give enough consideration to the needs of teachers and the requirements of curriculum reform. The purpose of the choice of the subject is to continuously inject confidence and motivation into new members of the learning community and to enable them to communicate in an atmosphere of equality, democracy, freedom. Therefore, we can make an organic combination of teachers' professional development and course resources construction.

4.2 The establishment of a reward mechanism in the construction of teaching resources

The implementation of the reward system on the one hand, can help teachers maintain the enthusiasm for resource construction and updating, and on the other hand, enhance the teachers' sense of the identity as being a member of the learning community. It can also prompt teachers to have a positive competition and thus realize common development for all those involved.

4.3The support of powerful learning tools and the collection of rich resources

A rich variety of resources are the essential nutrients for teachers' teaching and researching activities.

4.4 Online and offline activities should complement each other.

The focus of our efforts is the construction 
of the online learning atmosphere based on the internet technique. Most of the activities are designed to be held on the online learning community platform, such as the discussion and exchange of information and other activities. Attention should also be paid to the organization of various research groups to carry out a large number of offline activities, including collective lesson preparation, the public class, expert lectures observation and etc. For the college English teachers, the online learning community should also organize the experienced teachers to conduct public classes. Other kinds of gathering and collective activities are also needed to deepen the emotional tie among community members. These activities are beneficial and can arouse the enthusiasm of members of the community, and enhance their sense of belonging.

\section{Conclusion}

The research and construction of the online learning community has important academic importance and practical significance, because the online learning community will definitely be an important tool in digital technology for the talent training work, such as the occupational training of college teachers, in the era of information. Online learning community can provide specific operating mode for the application of this new media. It can also help solve many of the existing problems in traditional training and opened new possibilities for occupational training. In the internet environment the online learning community made it possible for teachers' professional learning and teaching practice, individual learning and cooperative learning as a group to be syncretized. It is possible to break through the limit of time and space. "The internet makes the cooperative learning community in the wide area possible. Through the interactive learning technology platform, real-time and non-real -time communication and cooperation between education experts can become reality."[5]

Acknowledgements

This work was financially supported by the Research Project of Shandong University at Weihai.

\section{References}

[1]. Cohran-Smith, M., \& Fries, K.. Researching Teacher Education in Changing Times: Politics and Paradigms. In C. Cochran-Smith \& K.M. Zeichner (Eds), Studying Teacher Education: The Report of the AERA Panel on Research and Teacher Education (PP.69-109). New Jersey: Lawrence Erlbaum Associates. (2005)

[2]. Xue Huanyu. An Initiative Investigation into the Theory and Practice of the Learning Community. Journalof University of Geosciences, 1 (2007)

[3]. Wang Xiaofang. From Community to Partnership: the Expansion and Reform of Teachers' Learning Situation. Journal of East China Normal University. 3. (2015)

[4]. Zhu Zhiting. Opportunities and Challenges brought by Cloud technology to the Informationization of Education in China. Chinese Audio-visual Education, 10. (2012).

[5]. Zhou Su. The Teacher Learning Community in the Internet Environment as a Support to Teachers' Professional Development. Electrochemical Education Research. 6. (2007) 